\title{
Cinema e intensidades: close-up e esgotamento
}

\section{Cinema and intensities: close-up and the exhausted}

https://doi.org/10.34112/2317-0972a2018v36n72p59-72

Érica SPeglich ${ }^{1}$

Antonio Carlos Rodrigues de Amorim ${ }^{2}$

RESUMO: A partir da produção audiovisual Jamais seque lágrimas sem luvas, buscamos analisar a construção das imagens em si, aceitando o convite de pensá-las em sua capacidade não de representar o movimento da realidade ou a realidade do movimento, mas talvez de conjugar, ou até conjurar, um outro plano de movimento e sentido, em especial, as formas de movimentação da câmera de aproximação ou close-ups e suas potências de construção de um sentido de esgotamento. As questões que nos movimentam são: por que essas imagens e palavras estão aqui? Que intensidades e encontros nos provocam? E, nos encontros com as provocações de Gilles Deleuze: o que a leitura dessas imagem ensinam ? $^{3}$

Palavras-chave: Cinema; close-up; esgotamento; imagens.

ABSTRACT: From the audiovisual production Don't ever wipe tears without gloves, we have analyzed the construction of the images themselves, accepting the invitation to think the images in their ability not to represent the movement of reality or the reality of the movement but, perhaps, to combine or even conjure another plane of movement ou another plane of senses, in particular, the movements of the camera, like the close-ups and its potency for the construction of a sense of exhaustion. The questions that have driven us

1. Universidade Estadual de Campinas, Campinas, SP, Brasil.

2. Universidade Estadual de Campinas, Campinas, SP, Brasil.

3. Apoio CNPq (processo n. 150603/2015-o). 
are: why are these images and words here? What strengths and meetings do they provoke? And, in the encounter with Deleuze's ideas: what do the readings of these images teach us? KeYwords: Cinema; close-up; exhaustion; images.

quando eu morrer, não quero choro nem vela quero uma fita amarela, gravada com o nome dela ${ }^{4}$

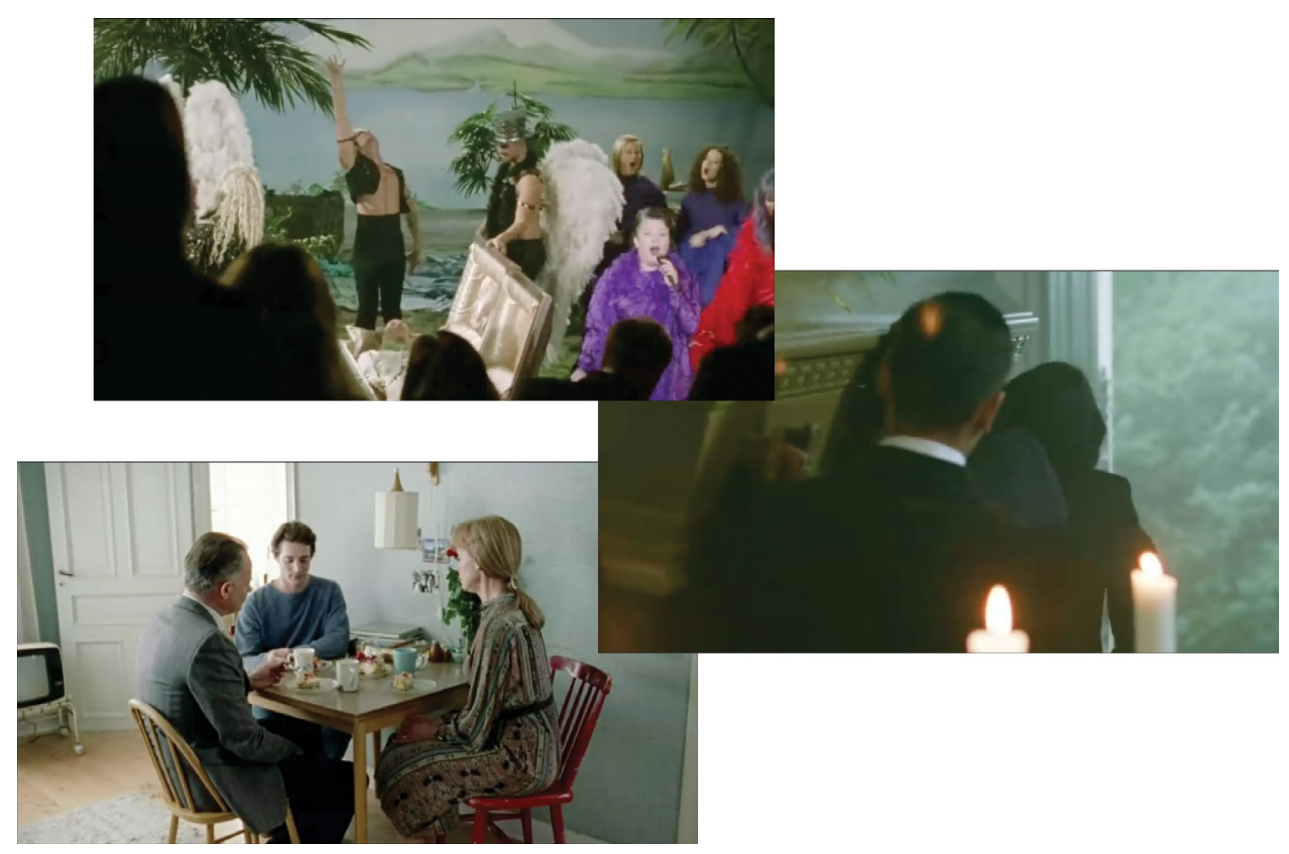

Figuras 1, 2 e 3 - Fotogramas de Jamais seque lágrimas sem luvas.

Muitas mortes e três funerais. Um funeral em vida que (re)começa. Outro em morte decidida como única forma de vida. $O$ terceiro em celebração de uma vida, sem choro nem vela. As cerimônias de morte de Benjamin, Bengt e Paul se entrelaçam e tiram o fôlego até uma sensação de esgotamento.

4. Samba "Fita Amarela", de Noel Rosa, composição de 1933. 
Essa história realmente aconteceu. E aconteceu aqui nesta cidade: Estocolmo, Suécia, final da década de 1980. Chegada da AIDS. Em uma série televisiva em três partes: O Amor - A Doença - A Morte. Jamais seque lágrimas sem luvas é uma frase que diz uma enfermeira a outra, mas ele estava triste. Uma tristeza que enche as telas em cenas enevoadas de uma infância leve e distante, narradas por um atual Benjamin envelhecido e saudoso de um passado cheio de amor, amizade e morte.

Estocolmo há 30 anos era uma cidade totalmente diferente do que é hoje. Pequena, escura e provinciana. Para gays só existia um lugar [... ] mas não nos atrevíamos a ir até lá. Mal existíamos. ${ }^{6}$ Benjamin narra seu encontro com um grupo de amigos e, especialmente, com seu amor - Rasmus. Juntos enfrentam as famílias e a invisibilidade imposta pela sociedade enquanto encaram as mortes pelo HIV e celebram o Natal com um grupo de amigos. Não tenho herdeiros, não possuo um só vintém. Eu vivi devendo a todos mas não paguei a ninguém. ${ }^{7}$ Grupo que vai desaparecendo aos poucos, restando apenas Benjamin e suas lembranças. Já viu, Rasmus, um alce branco? Não é albino, é diferente, simplesmente. E sabe de uma coisa? Nesta parte de Värmland há um rebanho de alces brancos. No passado, considerou-se que tinham poderes mágicos. E atirar neles dava azar. Mas quem atiraria em algo tão belo? Muitos que os acham diferentes. Que não deveriam existir. Mas existem. Sim, existem. ${ }^{8}$

Somos provocados pelas questões de uma das camadas inventivas propostas por Amorim (2014) para pensar as potências das audiovisualidades: por que essas imagens e palavras estão aqui? Que intensidades e encontros nos provocam?

5. Jamais seque lágrimas sem luvas (Torka aldrig tårar utan handskar) é o título da série. Uma produção televisiva Sueca, filmada e exibida em 2012 pela Sveriges Television e adquirida e exibida pela BBC em 2013 . O roteiro é de Jonas Gardell e a direção de Simon Kaijser, baseado em três livros de Jonas Gardell e suas experiências pessoais de vida na Estocolmo da década de 1980. A série trata dos encontros entre Benjamin (Adam Reier Lundgren), Rasmus (Adam Gustav Justus Pålsson), Paul (Simon Jönsson Berger), Bengt (Christoffer Svensson), Lars-Åke (Michael Jonsson) e Reine (Kristoffer Berglund) ao longo da década de 1980 na cidade de Estocolmo. Os trechos destacados em itálico são de falas das personagens e do narrador da série, referenciadas nas notas de rodapé.

6. Narração no Episódio 1 (30:33 minutos). A série é narrada a partir das memórias de Benjamin, anos depois da época retratada. A ênfase da narrativa é nas diferenças entre a Estocolmo do século XXI - considerada moderna e diversa - com a cidade da década de 1980. Os três episódios iniciam com as mesmas frases: O que é contado nesta história realmente aconteceu. E aconteceu aqui, nesta cidade. E foi como uma guerra, travada em tempos de paz. Em uma cidade onde a maior parte das pessoas continuava a viver suas vidas como se nada estivesse acontecendo, homens jovens ficaram doentes, definharam e morreram.

7. Samba "Fita Amarela", de Noel Rosa, composição de 1933.

8. Diálogo entre Rasmus (criança) e seus pais (Episódio 1 - 42:0o minutos). Entre o ir e vir temporal da série inserem-se também memórias da infância de Benjamim e Rasmus. A figura do alce branco aparece três vezes na série, sempre numa relação próxima com os acontecimentos da vida de Rasmus e como um ser mágico e, ao mesmo tempo, caçado pela sua diferença. 
Podemos olhar para as imagens como "lugares de criação", juntamente com Beatriz Furtado (2007) e seus pensamentos criados também no encontro com Gilles Deleuze. "Imagem-intensidade", um ato de criação "que não é privilégio da arte, mas parte de toda uma série de invenções, de funções, de blocos de duração, blocos de movimento, invenções de conceito, etc, séries que têm em comum, como lugares de criação, a constituição de espaços-tempo" (FURTADO, 2007, p. 48).

Imagens que geram um campo de intensidade, imagens que proporcionam encontros - com pensamentos, com sensações, com desaparecimentos - são esses encontros que nos forçam a pensar. "Há no mundo alguma coisa que força a pensar. Esse algo é objeto de um encontro fundamental, e não de uma recognição" (DELEUZE, 2006, p. 203). Intensidade da imagem que não se subordina ao real, que reivindica a produção, que exige uma vontade criadora (FURTADO, 2007, p. 57). E é o intensivo, ainda seguindo o pensamento de Deleuze (2006, p. 213) que é o objeto desse encontro que nos força o pensamento e, ao mesmo tempo, o intensivo é o objeto que o encontro faz tornar sensibilidade. De encontros restam "demônios, potências do salto, do intervalo, do intensivo ou do instante" (DELEUZE, 2006, p. 213) e não identificações ou recognições.

Caminhando com Deleuze em suas leituras de um Proust Em Busca do Tempo Perdido (2003), deparamo-nos com a proposta de um aprendizado sem compreensão, um aprendizado pelo que sentimos e não uma busca pela explicação, pelo entendimento. E continuando a caminhar com Gilles Deleuze em suas provocações para que tracemos linhas de fuga do pensamento da imagem como representação, como registro ou como comunicação. Deleuze nos convida a traçar essas linhas de fuga como novas possibilidades que, preferencialmente, não venham a ser novas explicações definitivas, mas linhas de fuga que possibilitem mais fugas, mais sentidos, mais deslizamentos; linhas de fuga que desemboquem numa redistribuição dos possíveis, no caso, dos possíveis de se pensar com imagens.

Algumas linhas intensivas de pensamento interligam as propostas deste texto com a proposta de Amorim (2012) de deslocar da mediação e apostar no estupor da audiovisualidade. "A potência da imagem 'em si': sua estranha capacidade enquanto uma imagem fixa, não de representar o movimento da realidade ou a realidade do movimento, mas talvez de conjugar, ou até conjurar um outro plano de movimento e sentido" (AMORIM, 2012, p. 55).

Procuramos analisar, nesta produção audiovisual, a construção das imagens em si, aceitando o convite proposto por essa linha intensiva de pensamento. Voltando 
às questões colocadas anteriormente: por que essas imagens e palavras estão aqui? Que intensidades e encontros nos provocam? E, nos encontros com as provocações de Deleuze: o que essas imagem ensinam?

As imagens dos funerais desses personagens vão esgotando as vidas e os sentidos de viver daqueles que (ainda) não morreram. Sobra a criação. Ou sobra a vida? Ou inicia-se outro possível de viver? "Em relação a que vai se definir o esgotamento, que não se confunde com o cansaço?” questiona Deleuze (2010, p. 89) para, logo em seguida, apresentar como potencialidades o leve recuo do centro, o desvio, o hiato, $o$ ato de se esgueirar, o pequeno, o salto. "Esgotar o espaço é exaurir sua possibilidade, tornando todo encontro impossível” (DELEUZE, 2010, p. 90). Formar séries exaustivas de coisas e mover-se por disjunções inclusas são modos apontados por Deleuze (2010, p. 86) para esgotar o possível. E e e e e. Ser judeu e ser gay e comemorar o Natal com gliter. 9 As imagens e sons em close são as que chamam a atenção ao longo desses funerais. São as mãos, olhares, suspiros, silêncios, pedaços de corpos que vão construindo, em close, a sensação de esgotamento. Para Martine Beugnet (2007, p. 89) o close-up é uma das técnicas mais potentes para um filme provocar um pensamento entre sujeitos e objetos, especialmente quando o cinema é um cinema da sensação:

Alternando entre dois pólos - a contemplação do imperceptível, da micro-vida, ou uma relação dramática com um corpo em mutação, é um mecanismo para nutrir o olho háptico, e não de passagem de informações psicológicas ou relações narrativas. Ele grava a metamorfose do corpo no lugar de reafirmar a identidade como uma continuidade ou coerência do mesmo.

São os close-ups que nos permitem fugir dos aspectos ligados unicamente à narrativa ou à caracterização das personagens e atentar para uma construção dos corpos. Corpos que vão se esgotando na passagem pelos diversos funerais. Dores, gritos engasgados, fúrias que podem ser sentidas na pele, numa sensação que se dá mais pelo tato que pela visão. "As imagens hápticas encorajam um modo de percepção visual que se liga ao sentido do tato, no qual o olho nos mostra sensações que usualmente seriam sentidas pela pele" (BEUGNET, 2007, p. 66).

9. Diálogo entre Paul e Benjamim (Episódio 1 - 23:0o minutos). Entre os momentos de encontro do grupo de amigos há um destaque para os Natais comemorados na casa de Paul e a construção destes como momentos familiares e do grupo como família. 


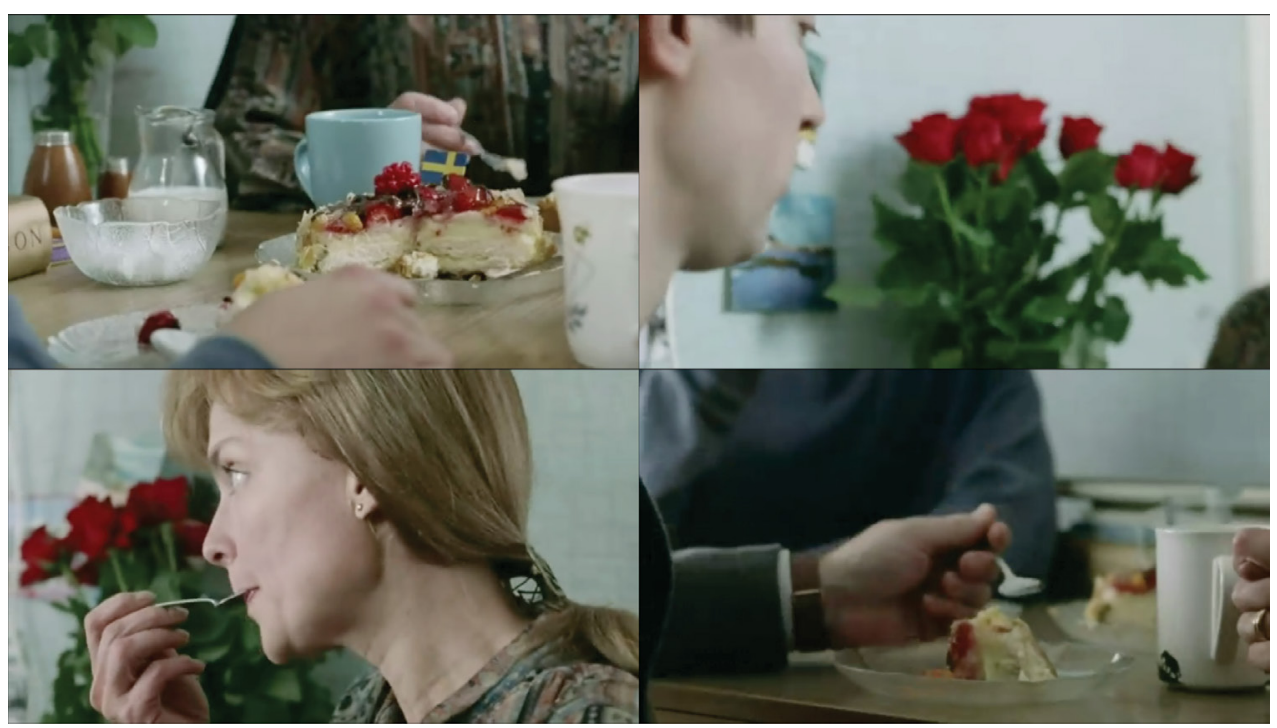

Figuras 4, 5, 6 e 7 - Composição com fotogramas do episódio 2 de Jamais seque lágrimas sem luvas.

O primeiro funeral que trazemos para compor este texto é o de Benjamin. O Benjamim do tempo presente narra os acontecimentos do passado, suas lembranças entremeadas pelos sentimentos de saudade, ausência, culpa. Memórias que surgem a partir da notícia da morte dos pais de Rasmus e, finalmente, a possibilidade que se abre de visitar o túmulo e dar adeus a seu amor.

O funeral de Benjamim foi em vida. Sua família é integrante das Testemunhas de Jeová e tanto seus pais quanto os outros integrantes de sua paróquia não aceitam sua homossexualidade e o excluem da comunidade religiosa à qual pertenceu a vida toda.

Em seu funeral em vida, os pais de Benjamin o visitam com rosas vermelhas e um bolo recheado de morangos e chantilly. Em cenas recheadas de silêncio e de conversas que nada dizem, cumprem o ritual de despedida do filho tal qual se despediriam de um morto. Tem que entender, eu te amo. Espero que esteja bem. Mas finjo que você não existe. ${ }^{10}$

Esgotado, extenuado, exaustivo, dissipado. "O esgotado é mais que o cansado" (DELEUZE, 2010, p. 67), pois o cansado não pode ou não consegue realizar mais nada e, no entanto, os possíveis permanecem mesmo que não realizados "porque nunca se

10. Carta a Benjamin, de sua mãe (Episódio 2 - 57:18 minutos). 
realiza todo o possível" (DELEUZE, 2010, p. 67). O possível, realizado ou não, movimenta-se dentro de projetos, objetivos, preferências, escolhas. Possível que exclui outros - projetos, objetivos, preferências, escolhas - possíveis. E exclui também outras realizações. "São essas disjunções exclusivas que acabam cansando" (DELEUZE, 2010, p. 69). Ou ou ou ou. Ou você segue a religião ou se apaixona por um homem. Ou você vive numa cidade pequena com sua família ou assume publicamente sua opção sexual.

Há cuidado e movimentos vagarosos na entrada dos pais no apartamento. Foco nas mãos que ajeitam os cabelos, os casacos na entrada, a saia no momento de sentar. Então você já sabe como é. Cortes nas imagens de um cômodo a outro (da cozinha em que está Benjamim à pequena sala onde sentam seus pais para comer bolo). Não precisa ser assim. Sons de passos, de talheres e copos sendo ajeitados, do trago na caneca de café. Precisa sim. Foco nas mãos que cortam o bolo, na caneca que vai à boca. Silêncio que se quebra não por sons, mas por olhares que se movimentam, questionam, se encontram e desviam. Ritmo de um ritual a ser cumprido. Suspiros e soluços silenciados, as rosas e o bolo... Este é meu próprio funeral. ${ }^{11}$

Não sou mau. Precisa ser assim. Não, não é mau, mas as coisas são assim. Um assim que, silenciosamente e entre focos em pequenos gestos, vai se re-afirmando como único possível no mundo dos pais de Benjamim e da comunidade religiosa de que sempre participou. E são esses silêncios e pequenos gestos que esgotam esse assim, esse possível para Benjamim.

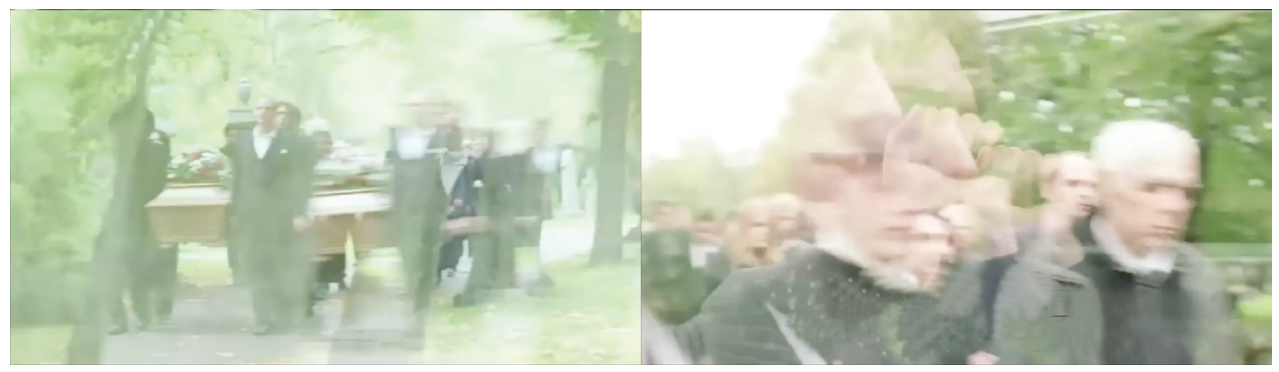

Figuras 8 e 9 - Composição com fotogramas do episódio 1 de Jamais seque lágrimas sem luvas.

11. Benjamim e seus pais (Episódio 2 - 43:13 a 43:41 minutos). 
Lamento informar que o resultado é positivo e que você tem ${ }^{12}$. Tem? Silêncio. Suspiros. Vazio. Gays e a AIDS mal existíam e continuavam tratados como inexistentes em funerais nos quais os companheiros/amores eram proibidos de comparecer. Namoradas surgiam com histórias de amor recheadas de músicas românticas para cantar e doações eram enviadas às fundações de combate ao câncer. Meus inimigos, que hoje falam mal de mim, vão dizer que nunca viram uma pessoa tão boa assim..$^{13} \mathrm{O}$ funeral de Bengt é uma surpresa para seus amigos, o primeiro funeral, do primeiro do grupo a morrer, já que ele decide pelo suicídio após descobrir a contaminação por HIV. A surpresa se dá menos pela morte de Bengt e mais pela cerimônia em si. Dor entrecortada pela desaprovação à presença dos amigos na igreja, pela reprovação por levarem o gato que pertecera a Bengt para o funeral, pelo aparecimento de uma suposta namorada desde a infância e suas canções de amor compostas para ele. Aquele belo rapaz não pôde nem viver direito sua vida, e agora negam o que ele viveu? ${ }^{14}$

Depois de Bengt vários amigos e conhecidos morrem e são enterrados em cerimônias muito parecidas. Imagens que se repetem até a quase exaustão: roupas escuras, caixões, flores, familiares em primeiro plano e amigos, namorados, amantes em segundo (ou em plano nenhum, já que proibidos de participar das cerimônias). Foco nas mãos que cortam o bolo, no garfo que vai à boca. Doações e mais doações a organizações de combate ao câncer, apresentado sempre e de novo e de novo e de novo como a causa da morte. Silêncios entrecortados por discursos que poderiam ser apenas murmúrios em sua falta de sentidos. Silêncios que se quebram não por esses sons, mas por olhares que se movimentam, questionam, se encontram e desviam.

O bom é que cada casamento... quero dizer, funeral, é uma repetição, ${ }^{15}$ sorri Paul, por volta do décimo funeral com as mesmas características.

12. Fala do médico a Bengt (Episódio 2 - 44:08 minutos). Há um movimento na série nos diálogos entre médicos e entre médicos e pacientes que traz a diferença do tratamento médico dado aos portadores de HIV e a compreensão da AIDS na década de 1980 e em 2012 (que seria o "presente" da série). No presente, Benjamin conversa tranquilamente sobre os remédios que toma, os indicadores de sua saúde e há um momento de aperto de mãos entre paciente e médico. Em 1980, entre médicos, o aviso de que não se pode secar as lágrimas sem luvas. E um médico que se dirige a Bengt sem ao menos conseguir elaborar a frase que passa o diagnóstico ao paciente. Um diagnóstico visto como sentença de morte.

13. Samba "Fita Amarela", de Noel Rosa, composição de 1933.

14. Fala de Paul (Episódio 3 - o6:49 minutos) durante o funeral de Bengt. A celebração dos funerais passava pela rememoração, por parte da família, da vida, amigos e realizações da pessoa morta. Frente à recusa em reconhecer publicamente a homossexualidade dos filhos e a morte decorrente da AIDS, os funerais na série se apresentam como celebrações de vidas inventadas que excluem parceiros e amigos.

15. Fala de Paul (Episódio 3 - 17:15 minutos). 
O estado de esgotamento não se confunde com a mera fadiga: esta última refere-se à incapacidade psicológica ou física para realizar qualquer outra coisa além do que já foi feito, enquanto que o primeiro pertence aos que exauriram todas as possibilidades, e indica algo mais ineliminável do que uma mera condição passageira. A diferença poderia ser expressa em termos leibnizianos: não mais existir no mundo atual, em um caso; não mais poder existir em nenhum mundo possível, no outro. É ao esgotado, àquilo que impede que qualquer novo possível seja dado porque todas as possibilidades foram percorridas. (PINHEIRO, 2012, p. 167).

São os closes nos olhares, mãos, garfos e copos que vão exacerbando os sentidos de esgotamento que perpassam as personagens. Beugnet (2007, p. 90) aposta na capacidade de ruptura dos close-ups, rupturas espaciais, temporais, figurativas e de percepção:

O close-up desloca o objeto do olhar, fragmenta-o e esculpe-o fora de seu meio $[\ldots] \mathrm{o}$ close-up leva a uma parada no fluxo da narrativa, gerando uma imagem quase estática [...] combinado com o efeito de isolamento e abstração do impacto da escala na tela do cinema, o close-up é dotado de uma força de interpelação, ele insiste, chama e direciona a atenção do espectador.

Nessa produção, o close-up chama a atenção para a exaustão de todas as possibilidades, nos movimentos de não mais poder existir em nenhum desses mundos possíveis.

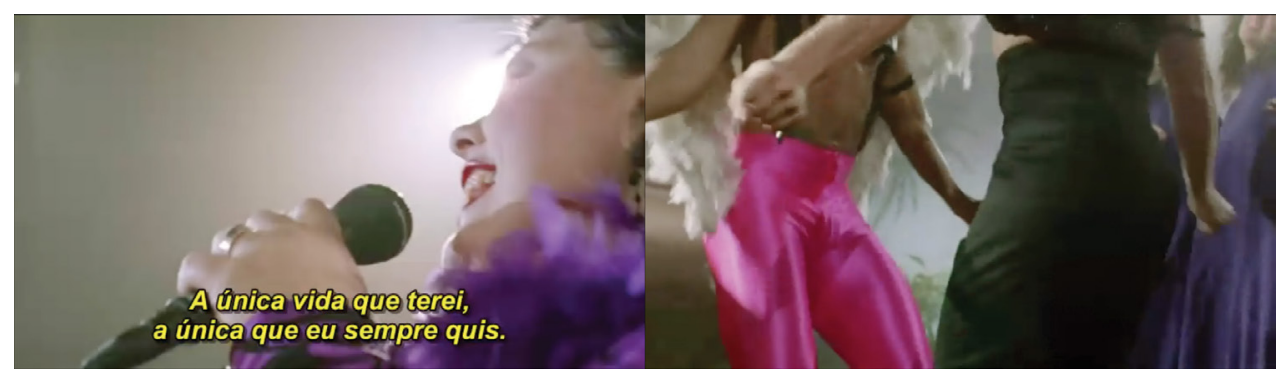

Figuras 10 e 11 - Composição com fotogramas do episódio 3 de Jamais seque lágrimas sem luvas.

O funeral de Paul é uma celebração da vida vivida. Um (último) ato de resistência. E um novo campo de possíveis criado. Será meu enterro e é tudo surpresa. Uma coisa 
posso afirmar: não haverá pastor falando sobre câncer. ${ }^{16} \mathrm{O}$ esgotado, por sua vez, esgota os possíveis e esgota “o que não se realiza no possível” (DELEUZE, 2010, p. 68).

Quando eu morrer, não quero choro nem vela. ${ }^{17} \mathrm{O}$ funeral acontece num teatro, com reserva de lugares para VIPs, e tem como pano de fundo uma paisagem típica dos cartões e materiais distribuídos pelas Testemunhas de Jeová com a representação do que seria o Céu: um monte Fuji ao fundo, que se mistura a uma paisagem tropical de coqueiros e árvores, grama (muito) verde e um leão. Há pastores e uma menina de vestido vermelho com cesta de piquenique repleta de frutas coloridas. Uma cópia da imagem do panfleto que Benjamim dá a Paul na primeira vez que se encontram, em uma das peregrinações dominicais de Benjamin para pregar a sua religião. O que quer que seja, desde que tenha aqueles desenhos fantásticos com mamãe, papai e filhos fazendo piquenique com um tigre e uma ovelha próximos a um lago nos Alpes [... me ajoelharei quando quiser. Uma seita que produz fantásticos kitsches... já estou dentro. ${ }^{18}$

Paul organiza uma festa com direito a coro, dança, anjo negro e paetês. Aqui estão meus desejos desenfreados, esta é a porra da minha transgressão. Aqui está meu orgulho, então olhe para mim. Aqui está minha vontade de viver. ${ }^{19} \mathrm{O}$ ritmo das imagens é de vídeo clipe: cortes rápidos para abranger toda a movimentação de palco, foco nos sorrisos e movimentos dos bailarinos. O corpo de Paul dentro do caixão no meio do palco se perde entre dança, brilhos e música. $\mathrm{O}$ foco da cena é para o show, para um funeral que é a porra da minha transgressão. A câmera que passa muito rapidamente pelo caixão no meio desta movimentação faz com que a atenção do telespectador, assim como a dos amigos e público do funeral, se volte cada vez mais para Paul, mesmo em sua quase ausência nas imagens. Então olhe para mim. Aqui está minha vontade de viver. ${ }^{\circ}$

Os close-ups desse funeral são em corpos que dançam, em bocas que cantam, em brilhos que se espalham. A música enche o espaço visual. Para Beugnet (2007, p. 91) a construção do espaço háptico pode se dar também pela trilha sonora. A autora trabalha com a ideia de close-up sonoro, quando a proximidade com um corpo ou um objeto pode ser evocada pelo som, na ausência de imagens.

\footnotetext{
16. Fala de Paul (Episódio 3 - 17:31 minutos).

17. Samba "Fita Amarela", de Noel Rosa, composição de 1933.

18. Paul, na primeira vez que encontra com Benjamim (Episódio 1-23:15 minutos).

19. Funeral de Paul (Episódio 3 - 50:42 minutos).

20. Funeral de Paul (Episódio 3 - 50:42 minutos).
} 
Síncrono ou assíncrono, preciso e hiper-detalhado ou apenas um eco, o close-up sonoro puxa o espectador e o envolve com um sentido de intimidade sensual ou estranho ou dá um grande poder ao sentimento de repulsa por um contato excessivamente próximo a algo desprezível (e, onde a imagem não mostra, o som alimenta sinestesicamente sua presença na imaginação do espectador e dá materialidade ao invisível). (BEUGNET, 2007, p. 81).

As cenas do funeral de Paul trazem, sem mostrar, a ausência das lágrimas e das revoltas no excesso da música que enche o ambiente, a cena, o filme, a pele. Trazem, também, na quase ausência de Paul e de narrativas sobre sua vida, a sua presença por meio da música e da dança. Se já se esgotaram todos os possíveis de se viver num mundo, Paul cria novos possíveis a partir dessa celebração, de corpos que insistem em celebrar a vida e, e, e...

São distintos os movimentos para o campo da educação e da leitura de imagens que advêm dos resultados da pesquisa a que este texto se vincula ${ }^{21}$. Na série de TV Jamais seque lágrimas sem luvas, tendo como contexto sociocultural a AIDS nos anos 1980 na Suécia, o trabalho com as imagens indica como se esboçam linhas de espaçamento e intervalos de figuração dos sujeitos: negados, silenciados, lacunares.

Essas formas incorpóreas dos sujeitos, possibilitadas pela leitura das imagens que realizamos, expressam-se nos modos como o close-up opera no cinema [e da qual a série de TV se apropriou tão bem] associando-os à interpelação da sensação. Essa dupla via leva-nos a uma reflexão sobre o impessoal e a indiferença. "Implícito e fragmento são nosso quinhão cotidiano, que cingem com suas franjas nossas palavras mínimas e os mais ordinários de nossos gestos; em seus interstícios, percebem-se os incorporais sob a forma do vazio, da perda, para não falar da desordem" (CAQUELIN, 2008, p. 200). Por fim, recorrer ao conceito de esgotado, extraído de Deleuze a partir dos estudos do teatro de Becket, permitiu-nos perceber o papel das imagens desde dentro de uma paisagem emocional, conceito importante para a compreensão sobre AIDS a partir da construção de sentimentos coletivos por meio de várias mídias, relatos, posições políticas etc, tanto com relação à comunidade gay, quanto ao HIV e à própria AIDS.

Nesse sentido, propusemos uma alternativa estética que a leitura das imagens e dos sons desta série televisiva nos permitiu. Adicionando algumas outras linhas

21. Projeto "Entrear audiovisuais: criações e pensamentos com a educação". Pós-Doutorado com financiamento do CNPq. Processo n. 150603/2015-o. 
que configuram os já consolidados argumentos a respeito da paisagem emocional sobre a AIDS, fruto do trabalho exaustivo de estudos de documentos de arquivo e depoimentos, desde 1987, coordenado por Matt Cook ${ }^{22}$.

Um dos conectores entre a pesquisa realizada por Cook e a série televisiva relaciona-se com a possibilidade de as famílias terem reconhecidos, socialmente, sua dor e sofrimento diante do fato de que ser gay, automaticamente no contexto das representações sobre a "epidemia de AIDS", significava uma sentença de morte. Ben Winyard, em seus comentários sobre a pesquisa de Matt Cook, observa que as mães de homens gays que estavam morrendo receberam uma cobrança moral, assumindo esse preço, quando falaram publicamente sobre seu sofrimento e dor, o que era frequentemente negado aos homossexuais. Winyard também observou que, nas respostas emocionais dominantes sobre a crise da Aids, os homossexuais raramente eram, se é que eram, entendidos ou representados como filhos, enquanto o sofrimento de seus pais era subestimado ou simplesmente ignorado.

No seu estudo, ressaltam-se, nas análises de propagandas em jornal impresso e televisivo, em testemunhos de agentes de saúde, familiares, amigos e colegas de trabalho - especialmente dos grupos que se identificam pela/com a heteronormatividade - e nos relatos de ativistas gays e portadores de HIV, o poder da loucura e da infelicidade; o papel dos pequenos gestos na constituição de uma comunidade de sentimentos/sensação; o significado do testemunho.

Em nossa análise, focando as imagens apresentadas neste artigo, enunciamos que o corpo esgotado de suas possibilidades reativas tem, em uma última resistência, o riso e o show, uma marcação da (re)insurgência do sujeito numa quase-vida, marcada sem a sua presença, mas num intervalo imaginal do ritornelo sonoro. São o implícito e o fragmento que "nos põem em contato com os incorporais e são eles que, curiosamente, estão o mais próximos de nós na vida corrente” (CAUQUELIN, 2008, p. 212).

Figurou-se, assim, como alternativa estética que a leitura das imagens e dos sons desta série televisiva nos permitiu: adicionar algumas outras linhas que configuram os já consolidados argumentos sobre a paisagem emocional sobre a AIDS.

22. Relato oral ocorrido na Inaugural Public Lecture by Birkbeck, University of London, em o1/12/2016. Archives of Feeling': the AIDS crisis in Britain c.1987. Palestra disponível em: <https://birkbeck.hosted. panopto.com/Panopto/Pages/Viewer.aspx?id=o8eb5dfd-c685-460c-9105-151aee841089>. Ver uma excelente síntese da palestra em: <http://blogs.bbk.ac.uk/events/2016/12/21/archives-of-feeling-the-aids-crisis-inbritain-c-1987/>. 
A partir da leitura de imagens da série de TV Jamais seque lágrimas sem luvas, acionamos os arquivos do sentimento em discussão, por exemplo, na pesquisa de Cook, e que proporcionam acesso imediato e móvel à gama de emoções vivenciadas por pessoas com AIDS e seus amigos e familiares, bem como os sentimentos de pessoas não diretamente afetadas. O implícito, insinuado pelos close-ups, é uma forma de memória sem memória "[...] que está o mais perto de corresponder o que pensamos sobre o exprimível incorporal: sabemos algo que não sabemos que sabemos, e só a ocasião certa permite acolher esse acolher não-sabido, permite trazê-lo ao real." (CAUQUELIN, 2008, p. 212).

Para além do que Cook indica ser possível observar dos "estilos emocionais e dinâmicos" e da exploração do "terreno emocional" negociado pelos indivíduos e ao longo dos arquivos de sentimentos de uma virtualidade latente que a série televisiva exprime; obtemos com as imagens, em seus interstícios e fragmentos de passagem, como as sensações - passíveis de serem transformadas em emoções - são regulamentadas, enquadradas e moldadas pela cultura. E apreendemos, com a leitura das imagens, a agir sobre um terreno que é profundamente comunitário e determinado por múltiplas forças fora do indivíduo. Posto que são incorpóreas, essas imagens são simultaneamente derivas de um mesmo tempo, fechado em si e reflexo do conjunto que o tempo, no intervalo que faz durar as imagens, condensa-as e as traz à luz.

\section{REFERÊNCIAS}

AMORIM, Antonio Carlos Rodrigues. Imagens para Nilda Alves; Nilda Alves entre imagens. Revista Teias v. 13, n. 29, p. 47-59, n. especial, 2012. . n-imagens. In: CAMARGO, Maria Rosa R. M.; LEITE, César Donizetti Pereira; CHALUB,

Laura Noemi (Org.). Linguagens e imagens. Educação e políticas de subjetivação. Petrópolis: DP et alii, 2014. p. 63-73.

BEUGNET, Martine. Cinema and Sensation: French Film and the Art of Transgression. Carbondale: Southern Illinois Press, 2007.

CAUQUELIN, Anne. Frequentar os incorporais: contribuição a uma teoria da arte contemporânea. Trad. Marcos Marciolino. São Paulo: Martins. 2008.

DELEUZE, Gilles. Proust e os signos. Trad. Antonio Piquet e Roberto Machado. Rio de Janeiro: Forense Universitária, 2003. .Diferença e Repetição. Trad Luiz Orlandi e Roberto Machado. 2. ed. Rio de Janeiro: Graal, 2006. . Sobre teatro: um manifesto de menos; O esgotado. Trad. Fátima Saadi, Ovídio de Abreu,

Roberto Machado. Rio de Janeiro: Jorge Zahar, 2010. 
FURTADO, Sylvia Beatriz Bezerra. Imagens que resistem. O intensivo no cinema de Aleksander Sokurov. 2007. Tese (Doutorado em Sociologia) - Faculdade de Sociologia, Universidade Federal do Ceará, Fortaleza, 2007.

JAMAIS seque lágrimas sem luvas (Torka aldrig tårar utan handskar). Direção: Simon Kaijser Produção: Sveriges Television. Intérpretes: Adam Reier Lundgren, Adam Gustav Justus Pålsson, Simon Jönsson Berger, Christoffer Svensson, Michael Jonsson, Kristoffer Berglund e outros. Roteiro: Jonas Gardell. Baseada nos livros “Jamais seque lágrimas sem luvas” de Jonas Gardell. PINHEIRO, Ulysses. Deleuze: Beckett, Leibnitz. Artefilosofia, Ouro Preto, n.13, p.154-166, dezembro 2012.

\section{SOBRE OS AUTORES}

Érica Speglich é graduada em Ciências Biológicas, tem Mestrado, Doutorado e Pós-Doutorado em Educação (Universidade Estadual de Campinas). É pesquisadora convidada do Laboratório de Estudos Audiovisuais OLHO na Universidade Estadual de Campinas e do Laboratório de Educação Ambiental OCA da Escola Superior de Agricultura Luiz de Queiroz. Participa do grupo de pesquisa MultiTão e da sub-rede de divulgação científica e mudanças climáticas no Laboratório de Jornalismo Científico da Universidade Estadual de Campinas. Interessa-se pelos encontros entre arte, educação e ciências. $\mathrm{O}$ período de estudos e escrita deste artigo foi realizado com o apoio do CNPq (Bolsa de PósDoutrado, processo n. 150603/2015-0).

E-mail: speglich@gmail.com.

Antonio Carlos Rodrigues de Amorim possui graduação em Biologia (Universidade Federal de Viçosa), Mestrado e Doutorado em Educação (Universidade Estadual de Campinas) e Pós-doutorado em Mídia e Comunicação (Goldsmiths College, University of London). É professor no Departamento de Educação, Conhecimento, Linguagem e Arte e pesquisador do Laboratório de Estudos Audiovisuais OLHO e do Laboratório de Estudos Avançados em Jornalismo - LABJOR, na Universidade Estadual de Campinas (UNICAMP). Tem experiência de pesquisa na área de educação, com ênfase nas relações entre currículo e culturas audiovisuais e na área de divulgação científica e cultural. E-mail: acamorim@unicamp.br.

Recebido em 02 de abril de 2017 e aprovado em 19 de maio de 2017. 